\title{
Inherited Metabolic Myopathies: Current Diagnosis and Treatment Approaches
}

\author{
Kalıtsal Metabolik Miyopatiler: Güncel Tanı ve Tedavi Yaklaşımları
}

\author{
(D) Melike Ersoy
}

University of Health Sciences Turkey, Bakırköy Dr. Sadi Konuk Training and Research Hospital, Clinic of Pediatrics, İstanbul, Turkey

\begin{abstract}
Inherited metabolic myopathies (IMMs) are a heterogeneous group of diseases characterized by inherited defects of enzymatic pathways involved in muscle cell energy metabolism. The worldwide incidence of genetic myopathies is about 1/3500, but the incidence of IMMs is unknown. Although it is considered rare compared with other hereditary myopathies, the expansion of neonatal screening programs and the increase in next-generation sequencing genetic methods for diagnosis have shown that the frequency is above the predicted rate. IMM is summarized as the name given to the group that includes defects in glycogen catabolism (glycogenolysis and glycolysis), fatty acid oxidation, Krebs cycle, or mitochondrial respiratory chain and oxidative phosphorylations. They have a broad clinical spectrum that can present symptoms of different severity at any stage of their lifetime. It differs from other myopathies in that they have unique clinical findings. Hence, it requires specific laboratory diagnostic methods and has specific treatments.

This review aims to make the differential diagnosis of metabolic myopathies from other structural myopathies and present current diagnosis and treatment approaches.
\end{abstract}

Keywords: Inherited metabolic myopathy, diagnosis, treatment

\section{öz}

Kalıtsal metabolik miyopatiler (KMM), kas hücresi enerji metabolizmasında rol oynayan enzimatik yolların kalıtsal kusurları ile karakterize heterojen bir hastalık grubudur. Dünya çapında genetik miyopatilerin insidansı yaklaşık 1/3500, ancak gerçek KMM insidansı bilinmemektedir. Yenidoğan tarama programlarının yaygınlaşması ve yeni nesil dizileme genetik yöntemlerinin artması ile diğer genetik miyopatilerle kıyaslandığında nadir olduğu düşünülse de, sıklığın tahmin edilen oranın üzerinde olduğu tahmin edilmektedir. KMM, glikojen katabolizması (glikojenoliz ve glikoliz), yağ asidi oksidasyonu, Krebs döngüsü veya mitokondriyal solunum zinciri ve oksidatif fosforilasyondaki kusurları içeren gruba verilen isim olarak özetlenmektedir. Yaşamın herhangi bir anında farklı şiddette semptomlarla ortaya çıkabilen geniş bir klinik yelpazeye sahiptirler. Kendine özgün klinik bulgulara sahip olmaları, spesifik laboratuvar tanı yöntemlerine ihtiyaç duymaları ve özgün tedavi şekilleri olmasıyla diğer miyopatilerden farklılık gösterirler.

Bu derlemenin amacı, metabolik miyopatilerin diğer yapısal miyopatilerden ayırıcı tanısını yapmak ve güncel tanı ve tedavi yaklaşımlarını sunmaktır.

Anahtar Kelimeler: Kalıtsal metabolik miyopati, tanı, tedavi

Address for Correspondence: Melike Ersoy, University of Health Sciences Turkey, Bakırköy Dr. Sadi Konuk Training and Research Hospital, Clinic of Pediatrics, İstanbul, Turkey

Phone: +90 2124147171 E-mail: zeynepcey@hotmail.com ORCID ID: orcid.org/0000-0002-2316-0790

Cite as: Ersoy M. Inherited Metabolic Myopathies: Current Diagnosis and Treatment Approaches. Med J Bakırköy 2021;17:108-114

Received: 18.05.2021

Accepted: 17.06.2021 


\section{INTRODUCTION}

Myopathies include the clinical disorders of the abnormalities of muscle cell structure or metabolism that lead to dysfunction. Disruption of muscle cells' structural integrity and metabolic status can result from inherited congenital abnormalities, external/internal toxins, inflammation, infection, and electrolyte imbalances. In addition, they can develop due to acquired or hereditary causes. Although they have a broad etiological spectrum, they are classified as the underlying causes (Table1).

Metabolic myopathies are a heterogeneous group of diseases with inherited defects of enzymatic pathways and signaling disorders involved in muscle cell metabolism (1). Furthermore, metabolic myopathies have only isolated muscle involvement and metabolic myopathies that may be associated with other system involvements (2). Metabolic myopathies have severe early manifestations in early childhood as well as late-onset adult types with mild symptoms. Both skeleton and cardiac muscle are high energy-consuming tissues. Exercise intolerance, muscle pain, muscle weakness and stiffness, rhabdomyolysis, myoglobinuria, cardiomyopathy (dilated, hypertrophic, restrictive) constitute general findings (3). Other accompanying involvements can also be related to liver, brain, eye, and glucose hemostasis with high energy requirements.

\section{Energy Metabolism Physiology of Muscle}

To understand the clinical findings of metabolic muscle diseases, explaining which substrates and enzymatic

Table 1. Classification of myopathies

\begin{tabular}{ll} 
Metabolic myopathies & Muscular dystrophies \\
\hline Glycogen storage diseases & Duchenne and Becker MD \\
\hline Fatty acid oxidation defects & \\
\hline Respiratory chain disorders & \\
\hline Congenital myopathies & Inflammatory myopathies \\
\hline $\begin{array}{l}\text { Central-core disease } \\
\text { Nemaline myopathy }\end{array}$ & Dermatomyositis \\
$\begin{array}{l}\text { Centronuclear (myotubular) } \\
\text { myopaty }\end{array}$ & Inclusion body myositis \\
\hline Congenital dystrophyies & Necrotizing myopathy \\
\hline $\begin{array}{l}\text { Muscle fiber (tybe 1-2) } \\
\text { Distribution disorder }\end{array}$ & Eosinophilic myositis \\
\hline & Granulomatous myositis \\
\hline $\begin{array}{l}\text { Endocrinological and toxic } \\
\text { myopathies }\end{array}$ & $\begin{array}{l}\text { Myopathies associated with } \\
\text { periodic paralysis }\end{array}$ \\
\hline
\end{tabular}

pathways the muscle uses during rest and exercise will facilitate understanding its pathology and preparing treatment protocols: Glucose, free fatty acids, and some amino acids and muscle creatine form the energy resources of the muscle (4). During the resting phase, the primary energy source is the mitochondrial beta-oxidation of free fatty acids (5). In the first phase of the exercise, glycogen stored in the muscle is used only for the muscle itself, unlike the liver. In the first few minutes of exercise, sufficient blood flow cannot be achieved yet. Energy is obtained by anaerobic destruction of muscle glycogen (6). Therefore, muscle glycogen, local blood glucose, high energy phosphate compounds are used in the intense short-term exercise. At the same time, free fatty acids are the main energy source in prolonged exercise and fasting.

Defects in any of these pathways glycogen catabolism (glycogenolysis and glycolysis), fatty acid oxidation, Krebs cycle, or mitochondrial respiratory chain and oxidative phosphorylation may cause myopathy $(7,8)$.

\section{Glycogen Storage Diseases}

Glycogen storage diseases (GSDs) are a large group of inherited metabolic diseases with abnormal storage or utilization of glycogen. Of the fifteen, GSD \| (acid alpha-glucosidase, Pompe), III (amylo-1,6 glucosidase, Cori, Forbes), V (myophosphorylase deficiency, Mc Ardele), VII [phosphofructokinase (PFK) deficiency, Tarui disease], VIII (phosphorylase b kinase deficiency), and X (phosphoglycerate mutase deficiency) are named "muscle glycogenosis" $(9,10)$.

GSD II: (Pompe disease) is a kind of lysosomal storage disorder caused by an accumulation of glycogen in the lysosome due to a deficiency of the acid alpha-glucosidase enzyme. The incidence of the disease is about $1 / 40,000$ according to the identified cases but is estimated to be more common than is detected by the widespread use of newborn screenings (11). It is classified in classic (infantile form), childhood, juvenile, and adult (late-onset forms) (12). Enzyme replacement therapy (ERT), which is a recombinant human GAA (rhGAA), has given a reasonable positive response $(13,14)$. The histopathological diagnostic findings are the vacuolization and autophagy in the muscle. The diagnosis of Pompe disease can be implemented by dried blood spot screening in suspected patients with high creatine kinase with or without cardiac involvement (15). In addition to ERT, positive, supportive effects of diet (high protein and branched-chain amino acids diets have been used as alternative energetic substrates) and benefits of the antioxidant treatments have also been reported (16). 
GSDV: GSDV (Mc Ardel) is characterized by exercise intolerance, muscle cramps, fatigue, weakness, with onset in late childhood. In half of the patients, muscle exercise results in massive creatine kinase elevation and rhabdomyolysis, leading to acute kidney failure. A block of muscle glycogen causes the disease to glucose-6- phosphate due to muscle glycogen phosphorylase deficiency (17).

After a few minutes of rest, patients with GSDV experience muscle pain and fatigue called the "second wind phenomenon." As indicated in the energy metabolism of muscle, fatty acids, the incapable of activating muscle glycogen stores, and patients' continuation of exercise are the leading causes of the "second wind phenomenon." The second wind does not occur in patients with other disorders associated with exercise intolerance (18). A recommended activity management targets to increase both capacity and muscle strength with the moderate-intensity exercise of 150 minutes per week distributed over 5 days per week to increase heart rate by $60 \%-70 \%(19,20)$. The diagnosis is based on the clinical features, subsarcolemmal vacuoles, and glycogen storage with absent myophosphorylase in the muscle biopsy.

Glucose or sucrose intake before exercise ameliorates symptoms in McArdle disease because the metabolic block is upstream of glucose catabolism, whereas it exacerbates muscle symptoms (21). Benefits from diets with high protein or a ketogenic diet, creatine monohydrate supplementation have been reported (22). Since myophosphorylase binds to vitamin B6, pyridoxine with fortified branched-chain amino acids diet may benefit GSDV (23).

GSD VII: GSDVII is characterized clinically by exercise intolerance, muscle cramps, weakness and stiffness in muscles, rhabdomyolysis as seen in GSDV, and an additional finding is a hemolysis (24). The deficiency of the muscle isoform of PFK results in loss of muscle cells and red cell PFK activity, respectively. Although it is generally diagnosed at advanced ages and with mild findings, it has been reported that it has a rare, rapidly progressive, fatal infantile form (25). Unlike GSDV, it is essential for the patient to listen to their body and avoid intense exercise and a diet containing high protein instead of glucose and fructose (26).

\section{Respiratory Chain Disorders (Mitochondrial Myopathies)}

Mitochondrial myopathies are the specific myopathies manifested by disruption in ATP synthesis due to genetic reasons that cause dysfunction of oxidative phosphorylation (OXPHOS) (27). The respiratory chain comprises four subunit enzymatic complexes $(\mathrm{I}, \mathrm{II}, \mathrm{II}$, and IV), which generate a proton gradient across the inner mitochondrial membrane that drives ATP synthesis by complex V (28). CoQ10 and riboflavin are critical components of the mitochondrial respiratory chain, serving as "electron shuttles" between the complexes $(29,30)$. Mitochondrial function is under the control of two genomes; mitochondrial genome (mtDNA) and nuclear genome (nDNA); there may be mitochondrial myopathy caused by pathogenic genetic variants found in any of these genomes. This dual genetic control causes different inheritance patterns [maternal (mtDNA), X-linked, autosomal recessive, autosomal dominant]. In addition, some common mitochondrial myopathies occur de novo (31).

Isolated muscle disease is rare in mitochondrial myopathies. It may affect one or more organs and systems with high energy consumption, such as the central nervous system, heart, liver, and eyes. Muscular findings of the patients can create different clinical phenotypes:

Chronic progressive external ophthalmoplegia (CPEO) can usually be associated with progressive ptosis and ophthalmoplegia with or without double vision and "myopathic face" appearance. CPEO can be seen as an isolated symptom or proximal myopathy, endocrinopathy, as in a Kearns-Sayre syndrome (32).

Proximal myopathy is the most common form of mitochondrial myopathy. Muscle weakness is variable and associated with fatigue. While some patients have a static course, in some patients, this weakness can progress gradually and affect the diaphragm and respiratory muscles, which can be life-threatening.

Exercise-induced muscle pain is a common finding and limits exercise tolerance. Unfortunately, this clinical variability is often confused with other types of muscle diseases by causing rhabdomyolysis.

Fatigue is one of the most common symptoms reported by patients. These cases constitute the most difficult group to diagnose. Disruption in performing simple everyday activities such as cutting with a knife, dressing, hair combing. This can cause psychiatric findings to accompany the clinic in individuals who had fatigue without myopathy.

It may also appear as a part of mitochondrial syndromes with combined system involvement such as Kearns-Sayre syndrome, Mitochondrial encephalomyopathy lactic acidosis, and stroke-like episodes syndrome, myoclonus epilepsy with ragged red fibers (33-35).

Diagnosis of mitochondrial myopathies requires a multidisciplinary approach. After history and physical examination, it includes routine biochemical tests, semi-specific metabolic tests, histopathological and 
immunohistochemical tests, enzyme levels of complexes, and genetic tests involved in specific oxidative phosphorylation. One of the hallmarks of mitochondrial myopathies is physiological tests, including oxygen production, consumption, and redox measurements (32). In addition, 31P nuclear magnetic resonance spectroscopy can measure decreased basal levels of high energy phosphate compounds. Today, for patients who cannot be diagnosed with targeted next-generation sequence analysis, gene tests for definitive diagnosis, WES or WGS tests are preferred.

Antioxidant effective coenzimq10, idebenone, riboflavin, nicotinamide, vitamins $C$ and $E$, lipoic acid, dichloroacetate, and ketogenic diet are applied the treatment with appropriate exercise programs. However, their effectiveness is limited, except for coenzimQ10 deficiency.

\section{Fatty Acid Oxidation Disorders}

Fatty acid oxidation (FAO) disorders are inborn lipid metabolism disorders caused by a deficiency of the enzymes needed to utilize fatty acids in mitochondria (36). The five types of FAO disorders present myopathic symptoms are primary carnitine deficiency, defects of betaoxidation and carnitine transport, multiple acyl-coenzyme A dehydrogenase deficiency, neutral lipid storage disease with ichthyosis (NLSD-I), and neutral lipid storage disease with myopathy (NLSD-M) carnitine palmitoyltransferase deficiency (CPT-II deficiency) (37,38). Carnitine and acylcarnitine profiles include diagnostic findings in tandem MS-MS spectrophotometry for FAO disorders. Its association with dicarboxylic aciduria (suberic, sebacic, adipic acid) in the organic acid profile supports suspicion.

Systemic primary carnitine deficiency: Primary systemic carnitine deficiency is due to a defect in the carnitine transporter (OCTN2) expressed in muscle, heart, kidney, and fibroblasts. This results in impaired FAO in skeletal and heart muscle in the foreground. In addition, renal and bowel wasting of carnitine results in low serum levels and diminished hepatic uptake of carnitine by passive diffusion, which impairs ketogenesis (39). Hypotonia, myopathy, cardiomyopathy (dilated, hypertrophic, or both), and hypoketotic hypoglycemia are the main symptoms. It is diagnosed with a markedly low level of free carnitine in tandem MS. However, it should not be confused with the nutritional carnitine deficiency in preterm and vegan mothers' babies. Carnitine replacement provides complete improvement of clinical findings. According to other FAO disorders, carnitine dosage may have to be increased up to $400-500 \mathrm{mg} / \mathrm{kg} /$ day. It is necessary to follow up with routine echocardiography to prevent heart failure due to cardiomyopathy.
Defects of beta-oxidation: Inborn errors of FAO result in energy failure, especially in the heart and skeletal muscle, by causing urinary excretion of acyl-carnitine and acyl-glycine conjugates resulting in secondary carnitine deficiency. Four acyl-CoA dehydrogenases are involved in mitochondrial FAO: short-chain, medium-chain, longchain, and very-long-chain acyl-CoA-dehydrogenases (SCAD, MCAD, LCAD, VLCAD) (40). Patients usually present an acute clinical attack with severe hypoketotic hypoglycemia, Reye-like acute liver and cardiac failure, and myoglobinuria due to rhabdomyolysis. In some cases, symptoms of muscle cramps, fatigue, and weakness can be observed without an acute metabolic attack. During acute metabolic decompensation, affected individuals should receive an intravenous glucose infusion at the rate of physiological glucose release by the liver according to the patient's age. It has been shown that carnitine intravenous replacement treatment can prevent secondary deficiency. Avoid prolonged fasting and excessive muscle egzersize in long-term treatment and provide energy with a dietary therapy based on fractionated meals rich in carbohydrates and medium-chain triglyceride (MCT) enriched low in fat. It is important for neurological development to supplement the patient with fish oil and walnut oil to avoid essential fatty acid deficiency (41).

\section{Multiple acyl-coenzyme a dehydrogenase deficiency} (MADD; glutaric aciduria type 2, GA2): MADD is an autosomal recessively inherited disorder of fatty acid, amino acid, and choline metabolism caused by mutations in 3 different genes: ETFA, ETFB, and ETFDH, which are involved in electron transfer in the mitochondrial respiratory chain. Certain type of FAO defect is also considered a mitochondrial disease. MADD is divided into 3 different groups depending on the heterogeneity of clinical findings: the neonatal-onset form with congenital anomalies; the neonatal-onset form without congenital anomalies; the lateonset form (42). Some of the neonatal-onset conditions can be lethal. Symptoms and age at presentation of late-onset MADD are highly variable and characterized by recurrent episodes of lethargy, vomiting, hypoglycemia, metabolic acidosis often preceded by metabolic attacks. Muscle involvement in the form of pain, weakness, and lipid storage myopathy occurs (43).

Riboflavin (vitamin B2) and CoenzimQ10 supplement often marked improvement of clinical weakness (100 mg 2-3 times daily, $15 \mathrm{mg} / \mathrm{kg} /$ day 2 times daily, respectively). A diet high in carbohydrates and low in fat and protein, with carnitine and MCT supplementation, avoiding long fasting periods are the long-term treatment targets. 


\section{Carnitine palmitoyltransferase deficiency (CPT-II} deficiency): CPT-II deficiency is the most commonly diagnosed disorder of fatty acid metabolism, in which a wide age range and spectral findings are detected. Although it is expected, many cases cannot be analyzed due to difficulties in diagnosis. The symptomatology usually consists of recurrent myalgias and muscle stiffness attacks with weakness and often associated with rhabdomyolysis. The patients are generally asymptomatic between attacks. Clinical symptoms usually are triggered by prolonged exercise or fasting, high fat intake, exposure to cold, viral infections, and even emotional stress, general anesthesia, or medications such as diazepam and ibuprofen. Besides carnitine and diet therapy, Triheptanoin, most likely, can correct the shortage of anapleurotic intermediates to the Krebs cycle (44).

Neutral lipid storage diseases (NLSDs): Refer to two different inherited disorders characterized by the enzymatic deficiencies affecting the lipase adipose triglyceride lipase and its coactivator CGI58 (45). NLSD-I (NLSD with ichthyosis) and NLSD-M (NLSD with myopathy) result in massive lipid accumulation in the leukocytes, skin, muscle, liver, bone marrow, and intestine. NLSD-I presents earlyonset ichthyosis associated with mild myopathy, while NLSD-M presents with muscle weakness and muscular atrophy in advanced cases (46). The effects of this defect are the alteration of energy production and the involvement of skeletal muscle that causes progressive myopathy and rarely cardiomyopathy. Muscle weakness is triggered by exercise, fasting, or infections. Unfortunately, no effective treatment exists to date for both NLSD-M and NLSD-M.

Diagnosis in inherited metabolic myopathies: Metabolic myopathies have a broad clinical spectrum, from infantile severe multisystemic disorders to adult-onset myopathies. To suspect these disorders, clinical features such as exercise intolerance and recurrent myoglobinuria need investigation while another group presents fixed weakness and cardiomyopathy as a clinical pattern. Therefore, when presented with such patients, it is most important to "think metabolic."

Before laboratory experiments, an exhaustive individual and family history, a neurological exam, exercise test, and neurophysiological exams are required. The inborn errors of metabolic disorders often present with muscle, heart, and central nervous system involvement. Therefore, their diagnostic workup includes sophisticated techniques ranging from simple biochemical tests to semi-specific and specific metabolic tests (Table 2).
However, now invasive procedures have been replaced by new-generation genetic (next-generation sequencing) diagnostic methods. In cases where structural and metabolic myopathies cannot be distinguished, next-generation sequencing-based "myopathy panels" that include many structural and metabolic genes can be studied.

Using algorithms in diagnosis will speed up the diagnosis and provide the rational use of expensive and timeconsuming genetic tests (Figure 1).

\section{Table 2. Diagnostic workup in inherited metabolic myopathies}

\begin{tabular}{ll}
\hline First-line tests & Second-line tests (functional \\
- Glucose, urea, creatinine, & tests) \\
LDH, CK, ALP, ALT, AST, & - Ischemic exercise test \\
phosphate, calcium, & - Exercise or bike ergometry \\
magnesium & test \\
- Thyroid function tests & - Fasting tests \\
- Myoglobin (urine) & Third-line tests \\
- Free and acylcarnitines (dry & - EMG \\
blood) & - Thorax radiography \\
- Lactate, pyruvate, ammonia & - ECG, ECHO \\
- Amino acids (serum) & - Muscle biopsy \\
- Organic acids (urine) & Genetic tests (NGS, WES, WGS) \\
\hline
\end{tabular}

ALP: Alkaline phosphatase, ALT: Alanine aminotransferase, AST: Aspartate aminotransferase, CK: Creatine kinase, ECG: Electrocardiography, ECHO: Echocardiography, EMG: Electromyogram, LDH: Lactate dehydrogenase, NGS: Next-Generation Sequencing, WES: Whole exome sequencing, WGS: Whole-genome sequencing

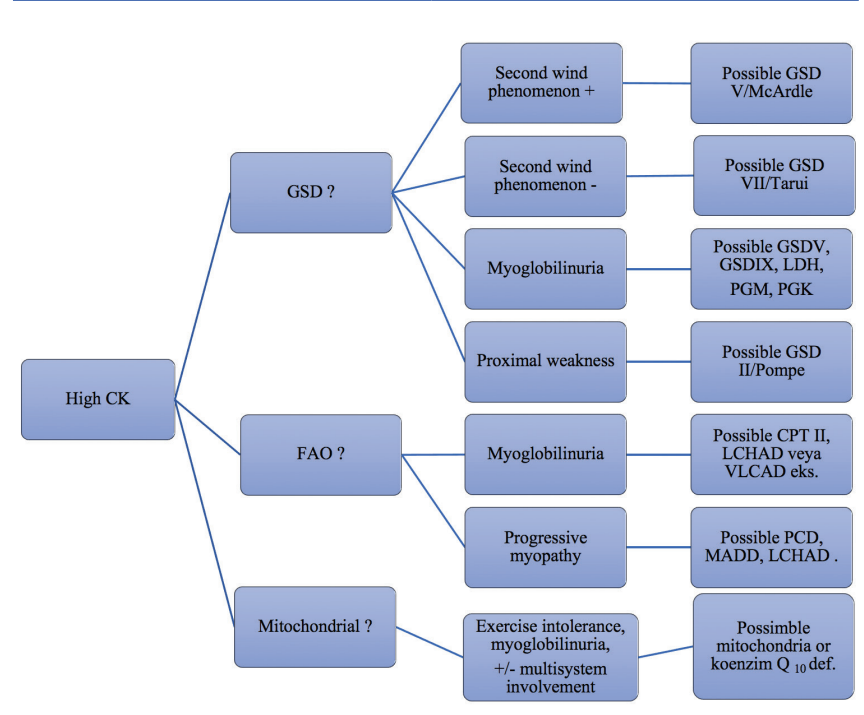

Figure 1. Diagnostic algorithm in inherited metabolic myopathies CK: Creatine kinase, CPT: Carnitine palmitoyltransferase, FAO: Fatty acid oxidation, GSD: Glycogen storage disease, LCHAD: Long-chain L-3 hydroxyacyl-CoA dehydrogenase deficiency, LDH: Lactate dehydrogenase, MADD: Multiple acyl-CoA dehydrogenase deficiency, PCD: Primary carnitine deficiency, PGK: Phosphoglycerate kinase deficiency, PGM: Phosphoglucomutase, VLCAD: Very longchain acyl-CoA dehydrogenase 


\section{CONCLUSION}

Metabolic myopathies should be considered in the differential diagnosis of exercise intolerance. A detailed clinical approach will help to determine which of the three main disorders (glycogenosis, lipid-related disorders, or mitochondrial diseases) is the underlying cause. Metabolic screening evaluates the second wind phenomenon and other related events, such as fasting, infections, and other catabolic situations. Further pre-exercise carbohydrate intake may provide additional clues to restrict the differential diagnosis. After "think metabolic" in diagnosis, metabolic screening tests should be included in the evaluation.

Treatment of metabolic myopathies primarily relies on avoiding precipitating factors and dietary supplements to bypass the metabolic block.

\section{ETHICS}

Financial Disclosure: The authors declared that this study received no financial support.

\section{REFERENCES}

1. Koo P, Sethi JM. Metabolic Myopathies and the Respiratory System. Clin Chest Med 2018;39:401-10.

2. Tarnopolsky MA. Metabolic Myopathies. Continuum (Minneap Minn) 2016;22:1829-51.

3. Finsterer J. An update on diagnosis and therapy of metabolic myopathies. Expert Rev Neurother 2018;18:933-43.

4. van Loon LJ, Greenhaff PL, Constantin-Teodosiu D, Saris WH, Wagenmakers AJ. The effects of increasing exercise intensity on muscle fuel utilisation in humans. J Physiol 2001;536:295-304.

5. Perry CG, Kane DA, Herbst EA, Mukai K, Lark DS, Wright DC, et al. Mitochondrial creatine kinase activity and phosphate shuttling are acutely regulated by exercise in human skeletal muscle. J Physiol 2012;590:5475-86.

6. Ørtenblad N, Westerblad H, Nielsen J. Muscle glycogen stores and fatigue. J Physiol 2013;591:4405-13.

7. van Adel BA, Tarnopolsky MA. Metabolic myopathies: update 2009. J Clin Neuromuscul Dis 2009;10:97-121.

8. DiMauro S, Lamperti C. Muscle glycogenoses. Muscle Nerve 2001;24:984-99.

9. Hedberg-Oldfors C, Mensch A, Visuttijai K, Stoltenburg G, Stoevesandt D, Kraya T, et al. Polyglucosan myopathy and functional characterization of a novel GYG1 mutation. Acta Neurol Scand 2018;137:308-15.

10. Preisler N, Haller RG, Vissing J. Exercise in muscle glycogen storage diseases. J Inherit Metab Dis 2015;38:551-63.

11. Tang H, Feuchtbaum L, Sciortino S, Matteson J, Mathur D, Bishop $T$, et al. The First Year Experience of Newborn Screening for Pompe Disease in California. Int J Neonatal Screen 2020;6:9.

12. van der Ploeg AT, Kruijshaar ME, Toscano A, Laforet $P$, Angelini $C$, Lachmann $\mathrm{RH}$, et al. European consensus for starting and stopping enzyme replacement therapy in adult patients with Pompe disease: a 10-year experience. Eur J Neurol 2017;24:768-31.

13. Angelini C, Semplicini C, Ravaglia S, Bembi B, Servidei S, Pegoraro $\mathrm{E}$, et al. Observational clinical study in juvenile-adult glycogenosis type 2 patients undergoing enzyme replacement therapy for up to 4 years. J Neurol 2012;259:952-8.

14. Angelini C, Semplicini C, Ravaglia S, Moggio M, Comi GP, Musumeci $\mathrm{O}$, et al. New motor outcome function measures in evaluation of late-onset Pompe disease before and after enzyme replacement therapy. Muscle Nerve 2012;45:831-4.

15. Nascimbeni AC, Fanin M, Tasca E, Angelini C. Molecular pathology and enzyme processing in various phenotypes of acid maltase deficiency. Neurology 2008;70:617-26.

16. Finsterer J. An update on diagnosis and therapy of metabolic myopathies. Expert Rev Neurother 2018;18:933-943.

17. Lucia A, Ruiz JR, Santalla A, Nogales-Gadea G, Rubio JC, GarcíaConsuegra I, et al. Genotypic and phenotypic features of McArdle disease: insights from the Spanish national registry. J Neurol Neurosurg Psychiatry 2012;83:322-8.

18. Angelini C, Semplicini C. Metabolic myopathies: the challenge of new treatments. Curr Opin Pharmacol 2010;10:338-45.

19. Godfrey R, Quinlivan R. Skeletal muscle disorders of glycogenolysis and glycolysis. Nat Rev Neurol 2016;12:393-402.

20. Haller RG, Wyrick P, Taivassalo T, Vissing J. Aerobic conditioning: an effective therapy in McArdle's disease. Ann Neurol 2006;59:9228.

21. Quinlivan R, Martinuzzi A, Schoser B. Pharmacological and nutritional treatment for McArdle disease (Glycogen Storage Disease type V). Cochrane Database Syst Rev 2014;2014:CD003458.

22. Vorgerd M, Zange J. Treatment of glycogenosys type $V$ (McArdle disease) with creatine and ketogenic diet with clinical scores and with 31P-MRS on working leg muscle. Acta Myol 2007;26:61-3.

23. Sato S, Ohi T, Nishino I, Sugie H. Confirmation of the efficacy of vitamin B6 supplementation for McArdle disease by follow-up muscle biopsy. Muscle Nerve 2012;45:436-40.

24. Musumeci O, Bruno C, Mongini T, Rodolico C, Aguennouz M, Barca $E$, et al. Clinical features and new molecular findings in muscle phosphofructokinase deficiency (GSD type VII). Neuromuscul Disord 2012;22:325-30.

25. Raben N, Sherman JB. Mutations in muscle phosphofructokinase gene. Hum Mutat 1995;6:1-6.

26. Haller RG, Vissing J. No spontaneous second wind in muscle phosphofructokinase deficiency. Neurology 2004;62:82-6.

27. Gorman GS, Chinnery PF, DiMauro S, Hirano M, Koga Y, McFarland $\mathrm{R}$, et al. Mitochondrial diseases. Nat Rev Dis Primers 2016;2:16080.

28. Alston CL, Rocha MC, Lax NZ, Turnbull DM, Taylor RW. The genetics and pathology of mitochondrial disease. J Pathol 2017;241:236-50.

29. Elston T, Wang $H$, Oster $G$. Energy transduction in ATP synthase. Nature 1998;391:510-3.

30. Noji H, Yoshida M. The rotary machine in the cell, ATP synthase. J Biol Chem 2001;276:1665-8.

31. Zhu X, Peng X, Guan MX, Yan Q. Pathogenic mutations of nuclear genes associated with mitochondrial disorders. Acta Biochim Biophys Sin (Shanghai) 2009;41:179-87.

32. Taivassalo T, Jensen TD, Kennaway N, DiMauro S, Vissing J, Haller RG. The spectrum of exercise tolerance in mitochondrial myopathies: a study of 40 patients. Brain 2003;126:413-23.

33. Zeviani M, Moraes CT, DiMauro S, Nakase H, Bonilla E, Schon EA, Rowland LP. Deletions of mitochondrial DNA in Kearns-Sayre syndrome. Neurology. 1988 Sep;38(9):1339-46. doi: 10.1212/ wnl.38.9.1339. PMID: 3412580.

34. Sproule DM, Kaufmann P. Mitochondrial encephalopathy, lactic acidosis, and strokelike episodes: basic concepts, clinical phenotype, and therapeutic management of MELAS syndrome. Ann N Y Acad Sci 2008:1142:133-58 
35. Wiedemann FR, Bartels C, Kirches E, Mawrin C, Wallesch CW. Unusual presentations of patients with the mitochondrial MERRF mutation A8344G. Clin Neurol Neurosurg 2008;110:859-63.

36. Goetzman ES. Advances in the Understanding and Treatment of Mitochondrial Fatty Acid Oxidation Disorders. Curr Genet Med Rep 2017;5:132-42.

37. Vasiljevski ER, Summers MA, Little DG, Schindeler A. Lipid storage myopathies: Current treatments and future directions. Prog Lipid Res 2018;72:1-17.

38. Angelini C. Molecular update and therapeutic trials in muscle disorders of glycogen and lipid metabolism. Paediatria Croatica 2003;47:61-7.

39. Lamhonwah AM, Olpin SE, Pollitt RJ, Vianey-Saban C, Divry P, Guffon N, et al. Novel OCTN2 mutations: no genotype-phenotype correlations: early carnitine therapy prevents cardiomyopathy. Am J Med Genet 2002;111:271-84.

40. Goetzman ES. Advances in the Understanding and Treatment of Mitochondrial Fatty Acid Oxidation Disorders. Curr Genet Med Rep 2017;5:132-42.

41. Madsen KL, Preisler N, Orngreen MC, Andersen SP, Olesen JH, Lund $\mathrm{AM}$, et al. Patients with medium-chain acyl-coenzyme a dehydrogenase deficiency have impaired oxidation of fat during exercise but no effect of L-carnitine supplementation. J Clin Endocrinol Metab 2013;98:1667-75.

42. Olsen RK, Andresen BS, Christensen E, Bross P, Skovby F, Gregersen N. Clear relationship between ETF/ETFDH genotype and phenotype in patients with multiple acyl-CoA dehydrogenation deficiency. Hum Mutat 2003;22:12-23.

43. Olsen RKJ, Koňaříková E, Giancaspero TA, Mosegaard S, Boczonadi V, Mataković L, et al. Riboflavin-Responsive and -Nonresponsive Mutations in FAD Synthase Cause Multiple Acyl-CoA Dehydrogenase and Combined Respiratory-Chain Deficiency. Am J Hum Genet 2016;98:1130-45.

44. Corti S, Bordoni A, Ronchi D, Musumeci O, Aguennouz M, Toscano $A$, et al. Clinical features and new molecular findings in Carnitine Palmitoyltransferase II (CPT II) deficiency. J Neurol Sci 2008;266:97103.

45. Pennisi EM, Garibaldi M, Antonini G. Lipid Myopathies. J Clin Med 2018;7:472.

46. Tavian D, Colombo R. Improved cytochemical method for detecting Jordans' bodies in neutral lipid storage diseases. J Clin Pathol 2007;60:956-8. 